\title{
Relative Processing Fluency
}

Current Directions in Psychological Science

2015, Vol. 24(3) 195-199

(C) The Author(s) 2015

Reprints and permissions:

sagepub.com/journalsPermissions.nav

DOI: $10.1177 / 0963721414561766$

cdps.sagepub.com

(S)AGE

\section{${ }^{1}$ Department of Consumer and Economic Psychology, University of Mannheim, and ${ }^{2}$ Department of}

Michaela Wänke ${ }^{1}$ and Jochim Hansen ${ }^{2}$ Psychology, University of Salzburg

\begin{abstract}
The subjective ease, or fluency, that is experienced during the cognitive processing of information has a large impact on the outcome of the processing. Research on judgment in a variety of domains shows that such fluency effects depend less on the (absolute) level of experienced fluency than on the relative fluency-that is, the change in fluency or the deviation from the expected level of fluency. Changes in an internal state are often more noticeable and perhaps more relevant as a diagnostic cue regarding the environment than the absolute level of that state. Relative experience is therefore particularly informative and accounts for ease-of-retrieval effects as well as classic fluency effects such as the truth effect and the mere-exposure effect.
\end{abstract}

\section{Keywords}

processing fluency, ease of retrieval, mere-exposure effect, truth effect

Judgments are influenced not only by the content of relevant information but also by the subjective experience of information processing. In particular, the experienced ease-or fluency-with which information is processed has an impact on a wide range of judgments. For example, stimuli are liked better (e.g., Bornstein, 1989; Winkielman \& Cacioppo, 2001) and statements are more likely to seem true (e.g., Hasher, Goldstein, \& Toppino, 1977; Reber \& Schwarz, 1999) when their perception feels easy (perceptual fluency). Attitudes and social judgments better reflect the content of recalled arguments or information when the recall is experienced as easy rather than difficult (retrieval fluency; for a review, see Wänke, 2013). Besides perception and retrieval from memory, many other cognitive processes create feelings of fluency (of disfluency) that in turn influence processing outcomes (for a review, see Alter \& Oppenheimer, 2009).

Reliance on fluency may be rational and adaptive because fluency represents a cue to the structure of the environment (Herzog \& Hertwig, 2013). Thereby, experiential states such as fluency have an informative value (Schwarz \& Clore, 2007). We propose a twist to this central assumption about metacognition, arguing that the current level of an experiential state may have less of an impact on judgments than its change from a previous level or deviance from an expectation.

At least two reasons prompt this hypothesis. First, cues have to be detectable. In order to be functional, they have to stand out against all the other stimuli in the external and internal environment. Changes in experiences or deviations from what is expected in a given situation are likely to be particularly salient. Second, granting that the fluency cue serves an adaptive function in the environment, changes in experienced fluency that signal changes in the environment should be particularly relevant because environmental changes call for a new appraisal of the situation and may require a change of strategies. For both of these reasons-cue detectability and cue relevance-responding to changes in the experiential state should be most adaptive.

Importantly, such changes from a baseline may constitute the deviation from one instant to another. An ongoing task may suddenly require more or less effort than before, or a new task may impose different demands than the previous one. Moreover, the specific context may evoke an expectation. Imagine going to lift a heavylooking barbell. One would prepare for a heavy weight and might not think much about it if the actual lifting confirmed this expectation. But if lifting revealed that the barbell were a dummy made of light plastic, the resulting experience would be more noticeable. Merely appraising

\section{Corresponding Author:}

Michaela Wänke, Department of Consumer and Economic Psychology, University of Mannheim, Parkring 47, 68131 Mannheim, Germany

E-mail: michaela.waenke@uni-mannheim.de 
a task or imagining doing it creates an idea of how easily one could do it. In fact, it has been shown that this expectancy suffices to elicit fluency effects. An advertising slogan that led individuals to expect that finding reasons for buying a brand was easy rather than difficult led to more favorable attitudes toward that brand (Wänke, Bohner, \& Jurkowitsch, 1997). Such expectancies may be explicit or implicit-that is, the individual may or may not be consciously aware of measuring the experience against a standard (Olson, Roese, \& Zanna, 1996).

In sum, we argue that, in particular, changes from a baseline or deviations from an expected experience trigger the use of fluency in judgments (for a review, see Hansen \& Wänke, 2013).

\section{Empirical Evidence for the Impact of Relative Versus Absolute Fluency Relative fluency and familiarity}

The first evidence that it is the deviation in rather than the (absolute) level of fluency that informs judgments was provided by Whittlesea and Williams (1998). They showed that feelings of familiarity emerged most strongly for stimuli that were processed more fluently than expected. Participants were asked to read aloud the items on a list of natural words (e.g., bottle) and nonwords (e.g., tlamnic) and to indicate which of the stimuli had been shown before. Words are visually more fluent than nonwords when merely read. However, some of the visually disfluent nonwords were surprisingly easy to pronounce and sounded like real words when read aloud (e.g., phrawg, which sounds like frog). Although processing latencies indicated that such pseudohomophones were less fluently processed than natural words, they were more likely to be erroneously "recognized" as having been encountered previously in the experiment than natural words. Apparently it was not just high fluency that indicated high familiarity but fluency that was relatively higher than expected based on spelling.

\section{Relative fluency and attitude judgments}

A classic finding in the fluency literature is that research participants report more favorable attitudes toward an issue after retrieving only a few favorable arguments for it compared with many favorable arguments (e.g., Wänke, Bless, \& Biller, 1996). This pattern reflects that the retrieval of a few arguments is experienced as easy but the retrieval of many as more difficult (Schwarz, Bless, Strack, Klumpp, Rittenauer-Schatka, \& Simons, 1991). In several studies, we replicated this classic paradigm but used different procedures to manipulate whether the level of fluency was congruent or incongruent with experimentally controlled expectancies (Hansen \& Wänke, 2008). In the most unobtrusive manner, we semantically primed the concept of ease or difficulty and thereby created a standard (Studies 1 and 2). We also directly manipulated expectancy (Study 3). Participants were asked to generate either two (easy) or eight (difficult) arguments that were either in favor of or against the idea of allowing political voting via the Internet. This target task was the last in a series of five tasks. The four preceding tasks were presented in either an increasing or a decreasing order of difficulty. Doing four increasingly difficult tasks induced an expectation that the following fifth task would be even more difficult, whereas a decreasingly difficult order led participants to expect an easy final task. The actually experienced ease or difficulty when retrieving either two or eight arguments, respectively, therefore either matched or mismatched participants' expectations. Only when ease of retrieval mismatched the expectation did we obtain the typical ease-of-retrieval effect (i.e., in which participants reported more favorable attitudes after retrieving two rather than eight supporting arguments or less favorable attitudes after retrieving two rather than eight opposing arguments).

\section{Relative fluency and trutb judgments}

In one of the most prominent fluency effects, the so-called truth effect, repeatedly presenting unfamiliar statements increases the likelihood that they will be believed to be true (e.g., Hasher et al., 1977). Repetition increases processing fluency, which in turn is attributed to the statements' validity (for a more detailed explanation, see Herzog \& Hertwig, 2013). In a test of the fluency account, Reber and Schwarz (1999) demonstrated that not only repetition but also visual fluency affects truth judgments. In this study, statements that were printed in colors with low contrast to the background (low perceptual fluency) were rated as less likely to be true than statements in higher contrast that were easier to read (high perceptual fluency). In the same manner, we presented participants with a high- or a low-contrast statement but manipulated whether or not the contrast differed from that of a series of preceding statements (Hansen, Dechêne, \& Wänke, 2008). In line with the relative-fluency account, when the fluency of a statement deviated from the fluency of the preceding statements, the truth effect was replicated: High-contrast statements were rated as more likely to be true than low-contrast statements. No effect, however, emerged when the statement's fluency (high or low) was similar to that of the preceding statements. These findings indicate that perceptual fluency informs judgments, particularly when the experienced fluency deviates from a "standard" experience. 
Relative fluency also accounts for the classic truth effect, whereby truth ratings of stimuli increase after repeated exposures: According to our assumptions, it is not merely the increase in fluency between the first exposure and repeated exposures that increases perceived truth. Rather, for the truth effect to occur, the heightened fluency (due to repetition) needs to diverge from a currently present standard. A closer look at the standard experimental procedure reveals that such a low-fluency standard is characteristic of many pertinent studies. The standard procedure involves presenting a full list of statements or stimuli at Time 1 and presenting some of these statements or stimuli (usually half) at Time 2. Importantly, at Time 2, the old items are intermixed with new items. The mix of old and new items creates differences in fluency, which, according to our assumption, drives the truth effect. Supporting this assumption, a meta-analysis of 51 studies on the truth effect revealed that differences in the perceived truth of old and new items at Time 2 were greater than truth differences for old items between the first and the second presentation (Dechêne, Stahl, Hansen, \& Wänke, 2010). Apparently, the truth effect is a function of the increased perceived truth of repeated items and the decreased perceived truth of new items due to fluency differences. Most crucially, as shown in another study, repeated items were rated as more likely to be true only when they were intermixed with new ones; no truth effect was observed when the repeated items were presented alone (Dechêne, Stahl, Hansen, \& Wänke, 2009).

\section{Relative fluency and the mere- exposure effect}

Similar to the truth effect, the mere-exposure effect occurs when repeatedly presenting previously unfamiliar stimuli increases liking-presumably as a result of the increased fluency of processing due to repetition (e.g., Bornstein, 1989). Again, the standard procedure involves presenting a mixed list of old and new stimuli at the test phase. As in our study on the truth effect, we compared the effects of repeated exposure with a mixed list versus a list of only repeated stimuli. Only when the old stimuli were mixed with new stimuli could the typical mereexposure effect be replicated: Repetition increased liking. When only old stimuli were presented, no increase in attractiveness ratings-compared with ratings of a control group—could be observed (Dechêne et al., 2009).

\section{Relative fluency and moral judgments}

Using the same paradigm of changes in figure-ground contrast as Hansen and colleagues (Hansen et al., 2008), Laham, Alter, and Goodwin (2009) found that descriptions of moral violations (for example, "A family eats its dead dog") were rated as less morally objectionable when they were printed in high contrast and were preceded by descriptions printed in low contrast. No such difference occurred when the level of fluency did not change from that of the previous descriptions.

\section{Does context affect the intensity of the experience or the use of the experience for judgments?}

The reviewed evidence supports our assumption that a discrepancy between the actually experienced fluency and a standard informs judgments, including social judgments. Our point is not that the context determines the intensity of fluency (or disfluency) like hot water makes lukewarm water feel cold by comparison. Rather, we propose that the context determines the diagnostic value of the experience. A change in the experiential state is usually more diagnostic than the current level of the experiential state.

We grant that both conceptions (intensity vs. diagnosticity) are difficult to disentangle and may not be completely independent of each other. We do not deny that the context may affect the perception of the experience. However, several findings speak against the notion of a mere change in the perceived intensity of the experience and support our notion concerning the diagnosticity of experiential changes. In the study described above (Hansen \& Wänke, 2008; Experiment 3), participants reported similar (high) levels of experienced ease after the retrieval of two (rather than eight) arguments irrespective of whether the ease of the task was expected or surprising. Likewise, they reported similar (and higher) levels of difficulty after the retrieval of eight arguments irrespective of expectations. Whereas self-reports showed that the context influenced whether the experienced level of ease or difficulty deviated from what was expected, it did not affect the intensity of the experience. Similarly, in the studies by Whittlesea and Williams (1998), familiarity was higher for pseudohomophones than for words despite the fact that the processing fluency of pseudohomophones was lower. Presumably, the deviance from the expectation was higher for pseudohomophones.

Additional evidence that context affects not merely the experience but the use of fluency has come from the studies by Dechêne and colleagues (2009) reported above. It seems unlikely that repetition did not lead to a more fluent processing of the stimuli when they were presented alone but did so only when they were intermixed with new stimuli. It seems more likely that the intermix of old and new stimuli made the difference between fluent and less fluent stimuli more salient. 


\section{Is it only relative fluency?}

We do not claim that the level of experienced ease (irrespective of the context) is completely irrelevant for judgments. Both changes in experiences and current states may of course be used as cues. Yet we would like to point out that there is less evidence for the impact of current states than one might assume. Standard experimental procedures may mask the impact of change in favor of the impact of the manipulated state. Notably, the experimental manipulation of the state always induces a change to a baseline or previous state. It is therefore an open question whether previous effects of an ease-of-retrieval or fluency manipulation were due to the manipulated state or rather to the change from a baseline (or the deviation from a standard). For example, reading a text printed in a difficult-to-read font is both difficult in general and also more difficult than one would expect when beginning to read a text. It should also be noted that in the classic ease-of-retrieval manipulation involving the retrieval of small versus large samples (Schwarz et al., 1991), experiencing change is inherent in the procedure: Even in the difficult condition, the retrieval of the first items feels easy (in fact, just as easy as in the easy condition). But whereas participants in the easy condition discontinue before the experience changes noticeably, participants in the difficult condition experience a change from ease to difficulty with additional retrieval.

\section{Conclusion}

Response sensitivity to changes in a state rather than current levels of that state is highly adaptive. Changes in the external world as well as internal states may signal that different behavioral strategies are needed to respond to the new situation. Moreover, changes foster detectability. Our perspective adopts these general mechanisms for predicting fluency effects. Numerous studies from our labs and others have shown evidence for the relativefluency account. This account holds implications for the emergence of such well-known phenomena as the easeof-retrieval, truth, and mere-exposure effects. From a broader perspective, this phenomenon need not be limited to the experience of fluency but may also hold for the psychological impact of other experiential cognitive states, such as moods or mind-sets, which may be a function of the relative change in, rather than the absolute level of, an experienced state.

\section{Recommended Reading}

Alter, A. L., \& Oppenheimer, D. M. (2009). (See References). A clear and recent overview of different sources and effects of processing fluency.

Hansen, J., \& Wänke, M. (2013). (See References). A recent and more detailed overview of the relative-fluency account.
Reber, R., \& Schwarz, N. (1999). (See References). A representative study on the truth effect.

Schwarz, N. (2012). Feelings-as-information theory. In P. A. M. Van Lange, A. Kruglanski, \& E. T. Higgins (Eds.), Handbook of theories of social psychology (pp. 289-308). Thousand Oaks, CA: Sage. An overview of different accounts and effects of processing fluency.

Wänke, M. (2013). (See References). A recent overview of the ease-of-retrieval effect.

\section{Declaration of Conflicting Interests}

The authors declared that they had no conflicts of interest with respect to their authorship or the publication of this article.

\section{References}

Alter, A. L., \& Oppenheimer, D. M. (2009). Uniting the tribes of fluency to form a metacognitive nation. Personality and Social Psychology Review, 13, 219-235.

Bornstein, R. F. (1989). Exposure and affect: Overview and metaanalysis of research, 1968-1987. Psychological Bulletin, 106, 265-289.

Dechêne, A., Stahl, C., Hansen, J., \& Wänke, M. (2009). Mix me a list: Context moderates the truth effect and the mereexposure effect. Journal of Experimental Social Psychology, 45, 1117-1122.

Dechêne, A., Stahl, C., Hansen, J., \& Wänke, M. (2010). The truth about the truth: A meta-analytic review of the truth effect. Personality and Social Psychology Review, 14, 238-257.

Hansen, J., Dechêne, A., \& Wänke, M. (2008). Discrepant fluency increases subjective truth. Journal of Experimental Social Psychology, 44, 687-691.

Hansen, J., \& Wänke, M. (2008). It's the difference that counts: Expectancy/experience discrepancy moderates the use of ease of retrieval in attitude judgments. Social Cognition, 26, 447-468.

Hansen, J., \& Wänke, M. (2013). Fluency in context: What makes processing experiences informative. In R. Greifeneder \& C. Unkelbach (Eds.), The experience of thinking: How the fluency of mental processes influences cognition and behavior (pp. 70-84). London, England: Psychology Press.

Hasher, L., Goldstein, D., \& Toppino, T. (1977). Frequency and the conference of referential validity. Journal of Verbal Learning and Verbal Behavior, 16, 107-112.

Herzog, S., \& Hertwig, R. (2013). The ecological validity of fluency. In R. Greifeneder \& C. Unkelbach (Eds.), The experience of thinking: How the fluency of mental processes influences cognition and behavior (pp. 190-219). London, England: Psychology Press.

Laham, S. M., Alter, A. L., \& Goodwin, G. (2009). Easy on the mind, easy on the wrongdoer: Discrepantly fluent violations are deemed less morally wrong. Cognition, 112, 462-466.

Olson, J. M., Roese, N. J., \& Zanna, M. P. (1996). Expectancies. In E. T. Higgins \& A. W. Kruglanski (Eds.), Social psychology: Handbook of basic principles (pp. 211-238). New York, NY: Guilford.

Reber, R., \& Schwarz, N. (1999). Effects of perceptual fluency on judgments of truth. Consciousness and Cognition, 8, 338-342. 
Schwarz, N., Bless, H., Strack, F., Klumpp, G., RittenauerSchatka, H., \& Simons, A. (1991). Ease of retrieval as information: Another look at the availability heuristic. Journal of Personality and Social Psychology, 61, 195-202.

Schwarz, N., \& Clore, G. (2007). Feelings and phenomenal experiences. In A. W. Kruglanski \& E. T. Higgins (Eds.), Social psychology: Handbook of basic principles (pp. 385407). New York, NY: Guilford Press.

Wänke, M. (2013). Almost everything you always wanted to know about ease-of-retrieval effects. In R. Greifeneder \& C. Unkelbach (Eds.), The experience of thinking: How the fluency of mental processes influences cognition and behavior (pp. 151-169). London, England: Psychology Press.
Wänke, M., Bless, H., \& Biller, B. (1996). Subjective experience versus content of information in the construction of attitude judgments. Personality and Social Psychology Bulletin, 22, 1105-1113.

Wänke, M., Bohner, G., \& Jurkowitsch, A. (1997). There are many reasons to drive a BMW: Does imagined ease of argument generation influence attitudes? Journal of Consumer Research, 24, 170-177.

Winkielman, P., \& Cacioppo, J. T. (2001). Mind at ease puts a smile on the face: Psychophysiological evidence that processing facilitation leads to positive affect. Journal of Personality and Social Psychology, 81, 989-1000.

Whittlesea, B. W. A., \& Williams, L. D. (1998). Why do strangers fell familiar, but friends don't? A discrepancy-attribution account of feelings of familiarity. Acta Psychologica, 98, 141-165. 